\title{
Moderasi Hukum Islam dalam Pemikiran Ahmad Hasyim Muzadi
}

\author{
Moh. Dahlan \\ (Pascasarjana IAIN Bengkulu, Jl Raden Patah Pagar Dewa Bengkulu, Email: \\ drdahlan@yahoo.co.id)
}

\begin{abstract}
Abstrak:
Penelitian ini bertujuan mengkaji paradigma ijtihad moderat Ahmad Hasyim Muzadi dan wacana moderasi hukum Islam yang dibangun oleh Ahmad Hasyim Muzadi. Adapun pendekatan kajian yang digunakan adalah pemikiran Milton K. Munitz, sedangkan metode kajian menggunakan metode induktif dan metode deduktif. Hasil penelitian menyebutkan bahwa paradigma ijtihad moderat yang dibangun oleh Ahmad Hasyim Muzadi tidak boleh hanya berlandaskan pada nash-nash hukum Islam, tetapi juga harus kaffah dengan cara berpikir yang jernih, tulus, dan ikhlas. Dengan cara demikian, wacana moderasi hukum Islam yang dihasilkan akan melahirkan sistem hukum yang inklusif dan akomodatif terhadap dinamika kehidupan manusia. Wacana hukum Islam yang memiliki keseimbangan dan berkeadilan dalam pemberlakuannya di tataran empiris.
\end{abstract}

Kata-kata Kunci:

Ijtihad, Hukum Islam, Moderasi, dan Muzadi

\begin{abstract}
:
This study aims to examine the paradigm of moderate ijtihad by Ahmad Hasyim Muzadi and moderation discourse of Islamic law that was built by Ahmad Hasyim Muzadi. This study used the approach is the thought of Milton K. Munitz, while the appraisal method using inductive and deductive methods. This study showed that the paradigm of moderate ijtihad that built by Ahmad Hasyim Muzadi should not be based on the texts of Islamic law only, but also to be devout and clear thinking, honest, and sincere. In this way, the moderation of Islamic law discourse that resulted will bear the legal system that is inclusive and accommodated to the dynamics of human life. Islamic legal discourse that has a balance and fairness in enforcement at the empirical level.
\end{abstract}

al-1hkâm Vol.11 No.2 Desember 2016

DOI 10.19105/al-ihkam.v11i2.1039 


\section{Key Words:}

Ijtihad, Islamic Law Construction, Moderation, and Muzadi

\section{Pendahuluan}

Sebagai bangsa yang majemuk, Indonesia memiliki komposisi etnis, suku, bahasa, ras dan agama yang kompleks. Hubungan di antara perbedaan sifat dan budaya itu menuntut upaya untuk mencari jalan keluar agar dapat hidup bersama dan damai. Prinsip hidup bersama dengan rukun dan damai menjadi nilai-nilai luhur yang dipelihara dan dilestasikan dalam ideologi Pancasila dan UUD 1945..$^{1}$ Komitmen untuk hidup rukun dan damai menjadi perhatian dalam hukum Islam karena prinsip hukum Islam itu dirumuskan dan diterapkan dengan landasan semangat kemaslahatan bagi umat manusia. Jika seseorang berada dalam kesulitan hidup, maka hukum Islam memberikan dispensasi dan kelonggaran demi tercapainya maslahah itu. Prinsip hukum Islam inilah yang telah memberikan warna dan cara tersendiri dalam proses penyebaran Islam di Nusantara melalui gerakan dakwah Walisongo.

Hukum Islam itu dibangun berdasarkan nilai-nilai prinsipil dan kemudian diterapkan dengan memperhatikan unsur-unsur kearifan lokal, yakni disampaikan dengan cara-cara yang santun, ramah dan harmonis, bukan dengan cara-cara kekerasan. Menurut Ahmad Hasyim Muzadi, gerakan Islam garis keras yang berkembang selama ini -seperti kaum radikal ISIS atau Negara Islam Irak dan Suriah, Wahabi dan Syiah- yang mengusung pemberlakuan hukum Islam dengan cara-cara kekerasan harus disikapi dengan serius dan dilawan dengan paham moderasi hukum Islam. ${ }^{2}$

Oleh sebab itu, cara berpikir demikian yang hendak didalami dalam kajian ini. Kenapa hal ini penting? Sebab, masyarakat Indonesia adalah masyarakat yang majemuk yang tidak bisa

\footnotetext{
${ }^{1}$ Moh Dahlan, “Gagasan Islam Kontemporer M Amin Abdullah”, Jurnal Academia Lemlit IAI Nurul Jadid, Vol. 02, tahun 2007.

2 Muhammad Makmun Rasyid, "Islam Rahmatan lil Alamin Perspektif KH. Hasyim Muzadi", Jurnal Epistemé, Volume 11, No 1 (Juni 2016), hlm. 110: Hasyim Jajaki Kerjasama Deradikalisasi dengan Australia, http://www.nu.or.id/post/read/56314/hasyim-jajaki-kerjasamaderadikalisasi-dengan-australia, (diakses tanggal 12 November 2016).
} 
ditangani dengan cara-cara kekerasan dan jalan pintas, tetapi harus berdasarkan penyelesaian yang komprehensif. ${ }^{3}$

Generalisasi masalah tidak akan menyelesaikan masalah sebagaimana penyelesaian masalah agama selama Orde Baru yang dilakukan dengan cara generalisasi/sentralistik. Setelah rezim tersebut tumbang, konflik mulai bermunculan mulai dari kasus Poso, kasus Ambon, dan kasus Sambas Kalimantan. Hal ini menunjukkan kerukunan dan kebersamaan selama Orde Baru dibangun bukan atas dasar kesadaran diri, tetapi akibat tekanan eksternal.

Masalah ini yang harus dipecahkan sebagai tantangan yang harus dihadapi dan dicari solusinya dengan baik. Sebab, represi politik bukan satu-satunya penyebab di era kekinian. Banyak faktor yang menyebabkan konflik seperti aksi-aksi terorisme dan ekstremisme yang masih menjadi. Maka kita harus kembali kepada kesadaran fitrah manusia, yakni bagaimana kita hidup damai dalam membangun masa depan umat Islam pada khususnya dan umat manusia pada umumnya.

Problem ini menjadi perhatian Ahmad Hasyim Muzadi dalam menyampaikan ajaran Islam rahmatan lil alamin demi kepentingan untuk membendung arus konflik yang bermotif agama dan nonagama. Ia menekankan telaah historis penyebaran Islam di Indonesia yang disyiarkan oleh Walisongo yang mengedepankan pesan-pesan perdamaian, kerukunan, keharmonisan dan kebersamaan yang saling menghargai dan menghormati. Itulah sebabnya, agama Islam dengan segala ajarannya termasuk hukum Islam, terinternalisasi dan tersosialisasi dengan baik dan masif di tengah-tengah warga masyarakat di Nusantara.

Dengan demikian, bukan dengan cara-cara kekerasan dan pemaksaan agama Islam disebarkan di Nusantara. Oleh sebab itu, Ahmad Hasyim Muzadi, menyatakan bahwa gerakan terorisme baik di dalam maupun di luar negeri pada dasarnya telah menumbangkan citra Islam rahmatal lil alamin. Aksi terorisme pada dasarnya sama dengan gerakan deislamisasi atau upaya penghapusan harkat ajaran Islam. Gerakan kaum teroris telah memberikan citra bahwa Islam adalah agama kekerasan. Sebab, jika agama disebarkan dengan cara-

\footnotetext{
${ }^{3}$ M. Amin Abdullah, Studi Agama: Normativitas dan Historisitas (Yogyakarta: Pustaka Pelajar, 1996), 5-6.
} 
cara kekerasan, maka yang akan terjadi adalah keengganan sasaran dakwah untuk membuka hati terhadap agama tersebut. 4

Berdasarkan uraian tersebut, kajian ini hendak merumuskan dua masalah, yakni bagaimana paradigma ijtihad moderat Hasyim Muzadi dalam membangun wacana moderasi hukum Islam? Bagaimana moderasi hukum Islam dibangun oleh Ahmad Hasyim Muzadi? Adapun kajian ini bertujuan meneliti paradigma ijtihad moderat Ahmad Hasyim Muzadi dalam membangun wacana moderasi hukum Islam dan wacana moderasi hukum Islam yang dibangun oleh Ahmad Hasyim Muzadi.

Pendekatan kajian ini menggunakan pemikiran Milton K. Munitz yang menyatakan bahwa pendekatan kajian keilmuan yang diperlukan saat ini adalah pendekatan keilmuan yang mampu mensinergikan antara universalitas dan partikularitas, normatifitas dan historisitas. Dengan sinergi itu, maka akan muncul moderasi wacana keilmuan, termasuk juga di dalam hukum Islam yang menjadi pembahasan kajian ini. Sementara itu, pendekatan kajian keilmuan yang memisahkan antara universalitas dan partikularitas, normatifitas dan historisitas tidak relevan lagi di saat ini, karena pemisahan wacana keilmuan itu bisa melahirkan rigiditas dan ekstrimitas, tekstual-radikal atau liberal-sekular. ${ }^{5}$

Adapun metode penulisan yang digunakan adalah metode deduktif untuk menjelaskan nilai-nilai moderasi hukum Islam dalam pemikiran Ahmad Hasyim Muzadi untuk diterapkan dalam tataran empiris-partikular, sedangkan metode induktif digunakan untuk menggali dan mengkritisi kenyataan empiris-partikular dalam upaya pembangunan dan penerapan hukum Islam agar bisa terimplementasi dengan dengan harmoni dan kondusif. ${ }^{6}$

\footnotetext{
4 Suryanto (ed.), "Terorisme Sama Dengan Deislamisasi", http://www.antaranews.com/berita/569356/terorisme-sama-dengan-

deislamisasi?utm_source=related_news\&utm_medium=related\&utm_campaign=news, (diakses tanggal 1 Agustus 2016)

${ }^{5}$ Milton K. Munitz, Contemporary Analytic Philosophy, (New York: Macmillan Publishing, 1981), 4-7.

${ }^{6}$ Ahmad Hasyim Muzadi, lahir di Bangilan, Tuban, 8 Agustus 1944. Ia adalah tokoh kharismatik di Indonesia. Adapun pendidikannya, pendidikan di Madrasah Ibtidaiyah di Tuban pada tahun 1950 , nyantri di Pesantren Gontor (1956-1962), dan menuntaskan pendidikannya tingginya di Institut Agama Islam Negeri Malang, Jawa Timur tahun 1969. Adapun kiprah organisasinya mulai dikenal luas sejak tahun 1992 sebagai Ketua Pengurus Wilayah Nahdlatul Ulama Jawa Timur yang kemudian Ketua PBNU tahun 1999 selama dua periode hingga 2010. Saat ini, ia
} 


\section{Paradigma Ijtihad Moderat dalam Pemikiran Ahmad Hasyim Muzadi}

Kajian ini melanjutkan dari karya tulis penulis yang berjudul, Gagasan Islam Kontemporer M Amin Abdullah, Jurnal Academia Lemlit IAI Nurul Jadid, Vol. 02 tahun 2007 dengan objek utama kajian ini adalah pembahasan kajian hukum Islam moderasi yang diutarakan Ahmad Hasyim Muzadi, sedangkan kajian sebelumnya fokus pada pemikiran kajian keislaman M Amin Abdullah secara global.

Kajian keilmuan ini merupakan keniscayaan karena manusia dan fenomenanya selalu mengalami dinamika dalam hidupnya, sehingga perlu terus dikaji dan dibangun berkesinambungan. Tidak ada pemikiran yang bersifat terpisah, tetapi selalu ada titik simpul yang saling terkait-mengait. Hal ini telah dibuktikan dalam kajian M. Francis Abraham yang mengkritisi cara berpikir yang memisahkan secara diametris antara budaya tradisional dengan budaya modern. Menurutnya, tidak ada masyarakat yang dapat dikategorikan murni tradisional dan juga murni modern tanpa pengaruh tradisi sebelumnya. Kemajuan peradaban Barat itu bukan karena memisahkan diri dari budaya lamanya, tetapi justru faktor kemajuan Barat karena berpijak pada tradisi lama secara kreatif (continuity of tradition). ${ }^{7}$

Demikian juga kajian ilmu hukum Islam yangdinamis, mem erlukan kajian yang berkesinambungan melalui ijtihad-ijtihad serius untuk menjawab masalah-masalah baru yang dihadapi umat Islam. Ahmad Hasan menyebutkan bahwa ijtihad adalah sebuah proses berpikir kembali dan melakukan penafsiran ulang terhadap hukum secara bebas (the process of rethinking and reinterpreting the law independently). ${ }^{8}$

menjabat sebagai anggota Dewan Pertimbangan Presiden sejak 19 Januari 2015. Adapun karya tulisnya adalah Pertama, Membangun NU Pasca Gus Dur, Grasindo, Jakarta, 1999. Kedua, NU di Tengah Agenda Persoalan Bangsa, Logo, Jakarta, 1999. Ketiga, Menyembuhkan Luka NU, Jakarta, Logos, 2002. Lihat https://id.wikipedia.org/wiki/Hasyim_Muzadi, (diakses tanggal 1 Agustus 2016); Fathurahman Djamil, Filsafat Hukum Islam, (Jakarta: Logos, 1997).

${ }^{7}$ M. Francis Abraham, Modernisasi di Dunia Ketiga: Suatu Teori Umum Pembangunan, terj. M. Rusli Karim, (Yogyakarta: Tiara Wacana, 1991), 1-28.

8 Ahmad Hasan, The Early Developmment of Islamic Jurisprudence, (Islamabad: Islamic Research Institute, 1970), 115-116. 
Prinsip yang disampaikan oleh Ahmad Hasan itu merupakan ijtihad mutlak karena tidak sekedar menerima dan membangun hukum Islam sesuai dengan kepentingan umat, tetapi juga dengan kesadaran yang dilandasi keimanan, ketulusan dan keilmuan yang mendalam dalam mendorong upaya-upaya penafsiran dan kajian kembali terhadap ketentuan-ketentuan hukum Islam yang ada. Hal ini dilakukan agar hukum Islam mampu menjawab segala persoalan masyarakat. Pendapat Ahmad Hasan tersebut adalah endapat mengenai ijtihad hukum Islam secara global.

Sementara itu, pendapat fuqahâ' yang membicarakan ijtihad hukum Islam secara khusus menerangkan bahwa ijtihad adalah segala daya upaya mujtahid yang dilakukan dengan penuh kesadaran, keimanan, ketulusan dan kedalaman ilmu untuk membangun ketentuan-ketentuan hukum Islam yang rasional-empiris yang bersumber dari al-Qur'an dan Hadis. Oleh sebab itu, seorang mujtahid dalam bidang hukum Islam harus memiliki syarat-syarat tersebut untuk menggali dan mendalami jawaban permasalahan berdasarkan nash-nash hukum Islam. Demikian tersebut karena problem hukum Islam itu berada dalam ranah yang rasional atau $m a^{\prime} q \hat{u} l$ al-ma'nâ (dapat dinalar). ${ }^{9}$

Dalam konteks Indonesia, Ahmad Hasyim Muzadi menyatakan bahwa saat ini muncul penilaian-penilaian subjektif yang dengan mudah menyudutkan pihak lain telah melanggar batas akidah. Gerakan takfîrî (pengkafiran) menjadi fenomena dan mengangap segala yang berbau budaya atau berbau Indonesia dianggap bid'ah. Gerakan takfîrî menyebarkan ajaran hukum Islam melalui cara-cara yang ekstrem dan keras. Kondisi ini sangat disayangkan karena para wali di masa lalu melakukan gerakan penyebaran ajaran hukum Islam kepada kaum kafir atau non-Muslim dengan cara-cara yang damai, rukun, harmoni dan santun. Sementara itu, pada saat ini banyak yang dikenal sebagai tokoh-tokoh Islam, tetapi justru dikafirkan oleh gerakan Islam garis keras seperti alQaeda. Ia merupakan gerakan takfiri bukan hanya kepada person, tetapi juga terhadap sistem negara, yang telah memberikan pengaruh terhadap sejumlah pelaku bom di Indonesia. Di Indonesia, ada

${ }^{9}$ Muhâmî Munîr Muhammad Thâhir al-Syawwâf, Tahâfut al-Qirâ'ah al-Mu'âshirah (Cyprus: AlSyawwâf li al-Nasyr wa al-Dirâsât, 1993), 450-452; Muhammad Kamâl al-Dîn Imâm, Ushûl alFikih al-Islâmî (Iskandariyah: Dâr al-Mathbû' al-Jâmi'iyyah, t.th.), 309-312. 
gerakan Angkatan Mujahidin Islam Nusantara (AMIN) yang merupakan kelmpok sempalan Darul Islam (DI)/Negara Islam Indonesia (NII), yang pernah melakukan aksi peledakan bom ${ }^{10} \mathrm{di}$ Masjid Istiqlal pada tanggal 15 April 1999.11

Akibat tindakan kekerasan itu, maka muncul persepsi yang salah di kalangan masyarakat, misalnya di Uni Eropa, dijumpai pandangan bahwa Islam dianggap sebagai agama yang mudah mengkafirkan pihak lain, melakukan pembunuhan, pembakaran rumah ibadah, bahkan sampai bom bunuh diri itu. Menurut Ahmad Hasyim Muzadi, pandangan mereka itu tidak sepenuhnya bisa disalahkan karena secara empiris-faktual telah terjadi sejumlah kekerasan yang dilakukan gerakan Islam garis keras seperti al-Qaeda, Angkatan Mujahidin Islam Nusantara, dan yang terbaru dilakukan gerakan ISIS atau Negara Islam Irak di Timur Tengah, walaupun hukum Islam pada dasarnya tidak mengajarkan tindakan kekerasan, tetapi hukum Islam justru mendorong terwujudkan kemaslahatan hidup manusia. ${ }^{12}$

${ }_{10}$ Hasil penelitian Fadjar I Thufail menyebutkan bahwa pasca reformasi 1998, maka kaum radikal dan fundamentalis agama menjadi berkembang pesat, sehingga intensitas konflik yang bernuansa agama juga meningkat. Fadjar I Thufail, "Ketika "Perdamaian" Terwujud di Bukit Kasih: Pencegahan Konflik, Lembaga Gereja, dan Politik Adat di Minahasa", Martinus Ramstedi dan Fadjar I Thufail (eds), Kegalauan Identitas: Agama, Etnisitas, dan Kewarganegaraan pada Masa Pasca-Orde Baru (Jakarta: Gramedia, 2011), 154.

11 Al-Qaedah adalah gerakan jihad kaum radikal yang dibentuk oleh Osama bin Laden pada tanggal 23 Februari 1998 dalam sebuah pertemuan di Kamp Khost, Kandahar untuk berperang melawan Yahudi dan kekuatan Salib. Perang melawan Amerika tidak saja dimaknai perang Osama bin Laden melawan Amerika, tetapi juga perang jihad antara kaum Muslim dan kaum kafir. Dr Azhari dan Noerdin M Top yang merupakan orang kepercayaan Hambali, melanjutkan program yang dirancang oleh al-Qaeda dan Hambali. As'ad Said Ali, al-Qaeda: Tinjauan SosialPolitik Ideologi dan Sepak Terjangnya, (Jakarta: LP3ES, 2014), hlm. 90 dan 248; Suryanto (ed.), "Terorisme Sama Dengan Deislamisasi", http:/ / www.antaranews.com/berita/569356/terorisme-sama-dengan-

deislamisasi?utm_source=related_news\&utm_medium=related\&utm_campaign=news, (diakses tanggal 1 Agustus 2016)

12 Hasil kunjungan ke negara-negara Uni Eropa dari Mantan Sekretaris Jenderal Pengurus Besar Nahdlatul Ulama (PBNU), Marsudi Syuhud, dijumpai pandangan di kalangan mereka bahwa Islam dianggap sebagai agama yang mudah mengkafirkan pihak lain, melakukan pembunuhan, pembakaran rumah ibadah, bahkan sampai bom bunuh diri itu. Namun, menurut Marsudi Syuhud, "Pandangan mereka terhadap Islam mulai berubah. Bahkan NU diminta untuk mengekspor paham keagamaan (Islam) yang dianutnya. Bayangkan, saat ini ada sekitar 169 masjid di Uni Eropa yang minta imam masjidnya dari NU. Ini menunjukkan paham Islam Ahlussunnah Waljaamaah menjadi perhatian dunia." Dengan diperkenalkannya wacana moderasi hukum Islam versi NU itu, masyarakat Uni Eropa kemudian berubah pandangannya terhadap agama Islam. Bagindo Armaidi Tanjung (Kontributor), Dulu NU Mengislamkan, Kini NU 
Menurut M Amin Abdulah, cara-cara beragama dan mengamalkan agama Islam, termasuk hukum Islam, dengan cara-cara kekerasan itu tidak akan menyelesaikan masalah walaupun misi dan tujuannya baik untuk mencapai ridla Allah dan surga. Bahkan sebaliknya, bukan mendapatkan ridla Allah, tetapi mendapatkan murka Allah dan balasan neraka. M Amin Abdullah menjelaskan:

Kecenderungan golongan garis keras (hard liners) yang kerap mempertontonkan agresivitas dan cara pendekatannya yang cukup emosional anehnya malah mendapatkan simpati di sebagian hati umat Islam sendiri. Barangkali karena aktivitas keseharian mereka kelihatan lebih bernyali, berani dan tegas dalam menegakkan kebenaran itulah yang kemudian melahirkan anggapan publik bahwa mereka lebih mewakili Islam ketimbang kaum moderat, progresif, ataupun liberal. Tetapi, bagi kaum moderat, tindakan yang mereka ambil itu tidak lain hanya untuk "menegakkan kepentingan" bagi diri atau kelompok mereka sendiri. Para penganut prinsip moderat, progresif dan liberal beranggapan bahwa cara-cara kekerasan yang dipergunakan untuk menyelesaikan masalah justru menciptakan masalah baru dan bersifat kontra produktif sehingga tidak jarang kemudian menyebabkan Islam sebagai agama yang kerap dituduh dekat atau identik dengan kekerasan dan terorisme menjadi sulit terbantahkan. Apalagi pasca peristiwa 11 September 2001, potret Islam sebagai agama beradab sayup-sayup digelontor oleh caci-maki, bahkan secara terang-terangan gerakan AlQaeda di Afghanistan dan Hizbullah di Lebanon dituduh sebagai biang keladi keonaran di muka bumi ini. Walhasil, lengkap sudah bukti-bukti yang menguatkan stereotip Barat atau non-Muslim terhadap Islam. ${ }^{13}$

Gerakan golongan garis keras (hard liners) yang mempertontonkan pendekatan agresif yang emosional, justru mendapatkan simpati di sebagian hati umat Islam yang awam

Dikafirkan, http://www.nu.or.id/post/read/35828/dulu-nu-mengislamkan-kini-nu-dikafirkan, (diakses tanggal 12 November 2016); A Hasyim Muzadi, Mengembangkan NU Melalui Penyembuhan Luka Bangsa (Jakarta: PBNU, 2002); lihat juga Muhammad Makmun Rasyid, "Islam Rahmatan lil Alamin Perspektif KH. Hasyim Muzadi", Jurnal Epistemé, Volume 11, Nomor 1 Juni 2016, 110.; Hasyim Jajaki Kerjasama Deradikalisasi dengan Australia, http:/ / www.nu.or.id/post/read/56314/hasyim-jajaki-kerjasama-deradikalisasi-denganaustralia, (diakses tanggal 12 November 2016).

${ }^{13}$ M Amin Abdullah, Pembaharuan Pemikiran Islam dan Perlunya Pendasaran Aqidah,, Makalah disampaikan dalam Seminar Internasional kerjasama Universitas Muhammadiyah Prof. Dr. HAMKA dengan Kerajaan Negeri Perlis Malaysia, Hotel Aryaduta, (Jakarta: 19 Februari 2007): http:/ /aminabd.wordpress.com/2010/04/30/pembaharuan-pemikiran-islam-dan-perlunyapendasaran-aqidah/, (diakses tanggal 12 November 2016) 
sebagaimana gerakan ISIS saat ini yang berkembang di Timur Tengah. ${ }^{14}$ Walaupun demikian, prinsip hukum Islam pada dasarnya tetap istiqamah dan konsisten sejak zaman Nabi hingga masa kini selalu menyuarakan perlunya menegakkan kemaslahatan dan sikap moderasi serta menolak cara-cara kekerasan dan kemadlaratan. Kenapa demikian, karena hal itu merupakan tujuan utama dari adanya legislasi hukum Islam, yakni untuk mewujudkan pemenuhan kebutuhan kemaslahatan hidup manusia yang hakiki baik kehidupan duniawi maupun ukhrawi. Oleh sebab itu, gerakan pengeboman dan teror yang dilakukan gerakan Islam garis keras tidak sesuai sama sekali dengan substansi dan tujuan utama dari hukum Islam. ${ }^{15}$

Dalam hal ini, Ahmad Hasyim Muzadi mengutarakan bahwa pemikiran hukum Islam yang memberikan garansi terwujudnya tata kehidupan umat Islam yang damai dan harmoni karena adanya ajaran hukum Islam yang diamalkan dan disebarkan dengan "jalan damai" yang berlandaskan kajian-kajian hukum Islam yang kaffah. Oleh sebab itu, pembangunan hukum Islam yang kaffah tidak bisa ditempuh dengan cara-cara berpikir yang sempit, dangkal dan emosional, tetapi harus dengan cara berpikir yang jernih, tulus, dan ikhlas dalam membangun dan mengamalkan wacana moderasi hukum Islam. ${ }^{16}$

Adanya perbedaan pendapat hukum itu harus dimaknai dan disikapi dengan arif. Keragaman disikapi dengan kebesaran jiwa dan akal pikiran untuk berlapang dada dan membuka. Kesamaan dan perbedaan digunakan sebagai media untuk saling melengkapi dan mendukung kemajuan bersama dan kerukunan hidup umat beragama di Indonesia. Penting untuk menghindari sikap mudah

14 Bagindo Armaidi Tanjung (Kontributor), Dulu NU Mengislamkan, Kini NU Dikafirkan, http://www.nu.or.id/post/read/35828/dulu-nu-mengislamkan-kini-nu-dikafirkan, (diakses tanggal 12 November 2016); lihat juga A Hasyim Muzadi, Mengembangkan NU Melalui Penyembuhan Luka Bangsa (Jakarta: PBNU, 2002).

${ }^{15}$ M Amin Abdullah, Pembaharuan Pemikiran Islam dan Perlunya Pendasaran Aqidah,, Makalah disampaikan dalam Seminar Internasional kerjasama Universitas Muhammadiyah Prof. Dr. HAMKA dengan Kerajaan Negeri Perlis Malaysia, Hotel Aryaduta, (Jakarta: 19 Februari 2007): http:/ /aminabd.wordpress.com/2010/04/30/ pembaharuan-pemikiran-islam-dan-perlunyapendasaran-aqidah/, (diakses tanggal 12 November 2016)

${ }^{16}$ Suryanto (ed.), "Terorisme Sama Dengan Deislamisasi", http:/ / www.antaranews.com/berita/569356/terorisme-sama-dengan-

deislamisasi?utm_source=related_news\&utm_medium=related\&utm_campaign=news, (diakses tanggal 1 Agustus 2016) 
tersinggung, marah, frustasi, dan dendam, tetapi sikap-sikap akhlakul karimah itulah yang hendaknya dipupuk dan dikembangkan untuk menghindari potensi konflik dan kerusuhan sosial, kekacauan, dan perseteruan antar agama. ${ }^{17} \mathrm{Di}$ sinilah pentingnya pendekatan multi dimensi dalam membangun kemajuan hidup beragama yang plural. Oleh sebab itu, studi agama (religious studies) termasuk juga kajian hukum Islam yang berlandaskan pendekatan multidimensi mendesak untuk digunakan dan dikembangkan. ${ }^{18}$

Dalam mengembangkan paradigma ijtihad moderat, Ahmad Hasyim Muzadi melalui Sarasehan Nasional, dengan tema "Potensi Pendidikan Islam Indonesia menjadi Rujukan Pendidikan Moderat Dunia," yang diselenggarakan oleh Direktorat Pendidikan Agama Islam, Kementerian Agama RI pada Senin 13 Juni 2016, menyampaikan bahwa secara garis besar, ada tiga paradigma ijtihad (hukum) Islam di Indonesia, yakni pertama, paradigma ijtihad tekstual; 'murni', sehingga pemahaman hukum agama dipahami secara harfiah tanpa ada pemaknaan dan pengertian yang mendalam, kontekstual, dan utuh terhadap nash-nash sumber ajaran Islam. Nalar hukum ini kaku dan sulit menerima pemahaman yang berbeda. Dalam bahasa Kaled Abou Fadl, paradigma ijtihad tersebut dikenal dengan paradigma ijtihad otoriter karena berlandaskan pada subjektifitas pribadi dengan menggunakan nash-nash hukum Islam.

Kedua, paradigma ijtihad moderat atau dalam istilah Khalid Abou Fadl dikenal dengan paradigma ijtihad otoritatif, yakni paradigma ijtihad yang berlandaskan pada nash-nash hukum secara benar, bukan subjektifitas pribadi yang tendensius. Paradigma ijtihad ini mengakomodasi perkembangan keadaan tanpa menggeser prinsip dan miqâd-nya. Gerakan dakwahnya tidak konfrontatif. Dakwah dijalankan dengan pendekatan persuasif. Menurut Hasyim Muzadi, paradigma ijtihad moderat inilah yang digunakan oleh para ulama (wali-wali) kita zaman dahulu dalam mengajarkan dan menyebarkan hukum Islam di Nusantara dan mengislamkan masyarakat Nusantara

\footnotetext{
${ }^{17}$ Achmad Syahid, "Peta Kerukunan Umat Beragama Propinsi Bengkulu” (Seri II), dalam Riuh di Beranda Satu, Peta Kerukunan Umaat Beragama di Indonesia, (Jakarta: Depag RI, 2003), 2.

18 M Amin Abdullah, Studi Agama..., 7-8; Greg Barton, Gagasan Islam Liberal di Indonesia; Pemikiran Neo-Modernisme Nurcholish Madjid, Djohan Efendi, Ahmad Wahib, dan Abdurrahman Wahid, terj. Nanang Tahqiq, (Jakarta: Pramadina, Pustaka Antara, dan The Ford Foundation, 1999), 3-4.
} 
dengan cara-cara damai, santun dan akomodatif. Mereka menggunakan prinsip-prinsip akhlakul karimah seperti prinsip i tidâl; tegak lurus; tidak ekstrem yang dikenal dengan istilah hanifiyah alsamhah: toleran yang tegak lurus. Dengan tanpa merendahkan agama lain, ajaran hukum Islam mampu diterima dengan baik dan masif di Nusantara.

Ketiga, paradigma ijtihad liberal adalah paradigma ijtihad yang menempatkan dan menjalankan hukum agama secara liberal sehingga agama cenderung ditarik untuk mengakomodasi dinamika keadaan saja kurang memperhatikan ajaran-ajaran hukum Islam. Paradigma ijtihad ini mendapatkan resistensi dari banyak kalangan umat Islam karena dinilai longgar.

Dengan demikian, paradigma ijtihad tekstual berkarakter tidak kompromis; paradigma ijtihad moderat berkarakter kompromis tetapi pada batas-batas yang tidak melanggar prinsip dan norma ajaran hukum Islam; dan paradigma ijtihad liberal yang bercorak liberal tanpa batas normatif. Oleh sebab itu, yang perlu didorong adalah membangun paradigma ijtihad moderat dalam membangun wacana moderasi hukum Islam. Dengan demikian, prinsip berpikir hanifiyah al-samhah harus menjadi pedoman, sehingga kita dapat beragama dengan cara yang sehat, seimbang, dan akomodatifselektif. ${ }^{19}$

\section{Wacana Moderasi Hukum Islam Ahmad Hasyim Muzadi}

Akar pemikiran wacana moderasi hukum Islam Ahmad Hasyim Muzadi pada dasarnya berdasarkan pada konsep Islam rahmatan lil 'alamin sebagaiamana pandangan Q.S al-Anbiya' (21): 107 yang di kalangan ulama ditafsirkan berikut: Pertama, Ahmad Mushthafa al-Marâghî berpendapat bahwa Allah tidak mengutus Muhammad dengan al-Qur'an ini dan yang serupa dengan itu berupa syari'at dan hukum yang menjadi pedoman kehidupan bahagia di dunia dan akhirat, kecuali untuk memberikan rahmat dan petunjuk bagi kehidupan umat manusia. Kedua, M. Quraish Shihab berpendapat bahwa eksistensi Nabi Muhammad saw adalah rahmat, bukan hanya membawa ajaran hukum, tetapi sosok dan kepribadian

19 "KH A Hasyim Muzadi, “Tiga Pola Pemikiran Islam di Indonesia”,

http://jakartanews.co/kh-hasyim-muzadi-tiga-pola-pemikiran-islam-di-indonesia/ (diakses tanggal 1 Agustus 2016) 
Nabi Muhammad saw adalah rahmat. Kepribadian Nabi Muhammad menjadi rahmat bagi orang yang meneladani, memahami, dan menghayatinya dalam kehidupannya. ${ }^{20}$

Meneladani keberhasilan Nabi Muhammad harus berdasarkan pada beberapa prinsip-prinsip berikut: Pertama, unsur rasionalitas karena keberhasilan Nabi tidak hanya karena unsur kerasulan dan kedekatan dengan Allah saja, tetapi karena usaha dan kerja kerasnya yang dilakukan sesuai sunnatullah. Kedua, unsur kecerdasan Nabi Saw dalam menjalankan kegiatan dakwah unutuk menganalisa dan mengambil kesimpulan atau keputusan yang tepat dan akurat yang terkadang tidak bisa dicapai oleh kebanyakan otak yang lain. Ketiga, unsur keseimbangan antara hati (heart) berupa spiritualitas dan moral; akal pikiran-wawasan intelektual (head), dan unsur kemampuan teknis (hand). Keempat, unsur komprehensif, bahwa ajaran hukum Islam yang dibawa oleh Nabi Muhammad SAW menyentuh semua esgi kehidupan sebagaimana yang dirumuskan oleh al-Syâthibî dengan istilah maqâshid al-syar'iyah (tujuan syari'ah/hukum Islam) yang meliputi pemeliharaan jiwa (hifdz alnafs), pemeliharaan agama (hifdz al-din), pemeliharaan akal (hifdz al'aql), pemeliharaan harta benda (hifdz al-maal), dan pemeliharaan keturunan (hifdz al-nasl). ${ }^{21}$

Dalam konteks ini, Ahmad Hasyim Muzadi merumuskan hal yang sama bahwa hukum Islam harus mampu memberikan ruang dan kesempatan untuk menciptakan kemaslahatan hidup manusia sehingga kedamaian dan kasih sayang bagi manusia maupun alam dapat terwujud dengan baik dan maksimal. ${ }^{22}$

\footnotetext{
20 Abuddin Nata, Islam Rahmatan lil Alamin Sebagai Model Pendidikan Islam Memasuki Asean Community, Makalah disampaikan pada acara Kuliah Tamu Jurusan Pendidikan Agama Islam Fakultas Ilmu Tarbiyah dan Keguruan UIN Maulana Malik Ibrahim Malang Senin, 7 Maret 2016 di Aula Lt. 5 Gedung Rektorat (Ir. Soekarno), (Malang: 7 Maret 2016), hlm. 3: http://fitk.uinmalang.ac.id/sites/default/files/materi/Materi\%20Kuliah\%20Tamu\%20PAI\%202016_.pdf, (diakses tanggal 12 November 2016)

21 Abuddin Nata, Islam Rahmatan lil Alamin Sebagai Model Pendidikan Islam Memasuki Asean Community, Makalah disampaikan pada acara Kuliah Tamu Jurusan Pendidikan Agama Islam Fakultas Ilmu Tarbiyah dan Keguruan UIN Maulana Malik Ibrahim Malang Senin, 7 Maret 2016 di Aula Lt. 5 Gedung Rektorat (Ir. Soekarno), (Malang: 7 Maret 2016), hlm. 3: http:/ fitk.uinmalang.ac.id/sites/default/files/materi/Materi\%20Kuliah\%20Tamu\%20PAI\%202016_pdf, (diakses tanggal 12 November 2016)

${ }^{22}$ Ahmad Hasyim Muzadi, Islam Rahmatan Lil'alamin Menuju Keadilan dan Perdamaian Dunia: Perspektif Nahdlatul Ulama, Pidato Pengukuhan Doktor Honoris Causa dalam Peradaban Islam disampaikan di Hadapan Rapat Terbuka Senat IAIN Sunan Ampel (Surabaya: 2 Desember
} 
Selanjutnya, secara historis, Ahmad Hasyim Muzadi, menyatakan bahwa pada awalnya sebagian besar umat Islam di Indonesia menganut ideologi Islam moderat yang disebut ahlu sunnah wal jamaah atau akrab dengan akronim aswaja yang terkonsolidasi ke dalam sistem negara yang berdasarkan Pancasila dan UUD 1945, tetapi akhir-akhir ini mengalami pergeseran dan pengaruh dari ideologi Islam trans-nasional yang banyak melakukan sejumlah tindakan yang tidak sesuai dengan nilai-nilai kebangsaan dan keIndonesia-an. ${ }^{23}$

Ideologi Islam trans-nasional itu memiliki pengaruh yang penting di Indonesia seperti al-Qaeda yang memiliki pengaruh terhadap aksi peledakan bom di sejumlah tempat di Indonesia, dan juga Ikhwanul Muslimin di Mesir yang juga mempengaruhi gerakan Usro sebagai bagian dari strategi baru dalam melakukan rekrutmen anggota baru karena gerakan DI/NII sudah kehilangan pengaruhnya, yang kemudian mendapatkan respons pengikut tidak hanya dari DI/NII, tetapi juga dari kalangan masyarakat perguruan tinggi. Tidak mengherankan jika gerakan usro yang dimotori Abdullah Sungkar24 itu tumbuh subur di sejumlah perguruan tinggi di Yogyakarta. ${ }^{25}$

Dalam menjawab masalah gerakan Islam garis keras itu, wacana moderasi hukum Islam harus ditumbuhkembangkan dengan masif untuk melawan paham dan wacana keilmuan hukum mereka yang radikal dan keras itu. Hal ini penting karena hukum Islam sebagai pedoman hidup umat Islam memiliki karakter akomodatif

2006): https://rachmatfatahillah.blogspot.co.id/2012/04/islam-rahmatan-lilalamin-dr-k-hhasyim.html, (diakses tanggal 12 November 2016)

23 Ruslani Burhani (ed), "Hasyim Muzadi: Radikalisme bukan Berasal dari Indonesia", http://www.antaranews.com/berita/571117/hasyim-muzadi-radikalisme-bukan-berasal-dariindonesia?utm_source=related_news\&utm_medium=related\&utm_campaign=news, （ diakses tanggal 1 Agustus 2016)

${ }^{24}$ Abdullah Sungkar adalah kawan akrab Abu bakar Ba'asyir yang dilahirkan di Klaten tahun 1937. Ia pernah aktif di kepanduan al-Irsyad dab GPII tahun 1954. Keduanya sudah pernah dibaiat masuk dalam gerakan NII tahun 1976. Setelah dibaiat keduanya mendapat mandat untuk mengembangkan gerakan Darul Islam di Surakarta dengan label baru. Nama ini sesungguhnya hanya bungkusnya saja, yang sebenarnya adalah Gubernur Militer NII Jawa Tengah. Keduanya juga pernah mengembangkan Jamaah Islamiyah di Solo yang menjadi cikal bakal dari gerakan usro. Bergabungnya kedua tokoh ke dalam NII kemudian menyebabkan perubahan haluan ideologi yang awalnya bermadzhab Syafii, mirip NU, menjadi wahabisme. As'ad Said Ali, al-Qaeda: Tinjauan Sosial-Politik Ideologi dan Sepak Terjangnya, (Jakarta: LP3ES, 2014), 138-139 dan 142.

${ }^{25}$ As'ad Said Ali, al-Qaeda: Tinjauan Sosial-Politik Ideologi dan Sepak Terjangnya, (Jakarta: LP3ES, 2014), 142-143. 
dan inklusif terhadap dinamika nilai-nilai hidup kemanusiaan dan kearifan lokal yang mana hal itu menjadi tujuan utama dari adanya legislasi hukum Islam untuk membangun kemaslahatan hidup manusia. ${ }^{26}$ Sikap akomodatif hukum Isam terhadap nilai-nilai kemanusiaan dan kearifan lokal tercermin dari salah satu prinsip pembangunan hukum yang dirumuskan Abdul Wahab Khallaf, di antaranya bahwa pembangunan hukum Islam harus berdasarkan kemaslahatan hakiki (al-mashlahah al-haqîqiyah) bukan berdasarkan kemaslahatan imajenatif (al-mashlahah-al-wahmiyah), pembangunan hukum berdasarkan kemaslahatan umum bukan hanya kepentingan personal/kelompok tertentu, dan pembangunan hukum Islam harus berdasarkan realitas aktual, tidak bisa digeneralisasi karena setiap zaman dan tempat memiliki nilai-nilai kemaslahatan yang bisa jadi tidak dijumpai di luar itu. ${ }^{27}$

Dalam konteks ini, wacana moderasi hukum Islam itulah yang cocok dan tepat untuk diterapkan di Indonesia sebagai negara yang majemuk dalam berbagai bidang termasuk dalam hal keyakinan keagamaan. Sejarah telah menunjukkan bahwa sejumlah konflik di Indonesia terindikasi bernuansa keagamaan. Demikian juga tindakan kekerasan dan aksi pengeboman di sejumlah tempat di Indonesia terkait dengan adanya paham (hukum) Islam yang tekstual dan ekslusif. Faktornya adalah tekstual dan eksklusifitas agama yang memang rentan benturan. Hal ini yang harus menjadi perhatian semua pemangku otoritas agama di Indonesia agar membangun kesadaran keberagamaan dan hukum yang inklusif-akomodatif sehingga terhindar dari potensi konflik agama.

Substansi semua ajaran agama pada dasarnya memiliki kesamaan prinsip, yakni untuk mewujudkan kebaikan, kedamaian dan kemaslahatan hidup manusia. Oleh sebab itu, jika terjadi konflik yang bermotif agama, maka hal itu pada dasarnya bukan berasal dari ajaran agama yang murni, tetapi faktor kepentingan lain yang menyeret agama ke dalam pusaran konflik atau bisa jadi wacana

\footnotetext{
${ }^{26}$ Ahmad Baidowi dkk. (eds.), Rekonstruksi Metodologi Ilmu-ilmu Keislaman, (Yogyakarta: Suka Press, 2003), 5.

${ }^{27}$ Menurut Abdul Wahhab Khallaf, tidak boleh ada generalisasi alias harus memperhatikan kearifal lokal dan dinamika zaman karena "pembangunan hukum terkadang memberikan manfaat pada suatu waktu tetapi pada yang lain justru membawa madlarat, demikian juga di suatu tempat membawa maslahah tetapi di tempat lain malah membawa madlarat". Abdul Wahhab Khallaf, Ilm Ushûl al-Fiqh, (Kuwait: Dar al-Qalam, t.th), 84-86.
} 
keagamaan hasil ijtihad kaum radikal itulah yang dijadikan dogma sehingga terjadi sakralisasi terhadap wacana keagamaan itu. ${ }^{28} \mathrm{M}$ Amin Abdullah mensinyalir bahwa gerakan radikal keagamaan Islam di Indonesia memiliki kecenderungan untuk menggunakan agama sebagai tameng kepentingannya. Mereka mengamalkan aspek legal formal agama dengan kepentingan bias pribadi dan golongan serta tidak secara utuh memahami nash-nash hukum agama.

Gerakan radikal keagamaan biasa ditampilkan oleh kelompok muslim puritan yang militan, jihadis, ekstremis, fundamentalis, radikal. Puritanisme di dunia Islam memiliki sejarah yang cukup panjang. Wahabisme dan salafisme merupakan gerakan sayap kanan Islam yang mempunyai andil besar menciptakan gerakan militan Islam di muka bumi ini. Dalam bentuknya yang lebih populer, banyak orang mengenal gerakan Ikhwanul Muslimin di Mesir dari Hasan al-Banna yang juga memberikan pengaruh di Indonesia dan juga al-Qaeda yang memberikan pengaruh terhadap aksi pengeboman di sejumlah tempat di Indoensia. ${ }^{29}$ Tetapi pada dasarnya, setiap gerakan keagamaan apapun namanya mempunyai tujuan mulia yakni menyebarkan pesan-pesan agama Allah dan risalah Rasulullah Muhammad kepada umat manusia.

Prinsip kembali ke al-Qur'an dan Hadits tentu bisa dipahami sebagai pemurnian atau purifikasi praktek keagamaan, tetapi alQur'an dan Hadits telah dibentuk oleh mereka -seperti al-Qaeda ${ }^{30}$ menjadi alat legitimasi yang memungkinkan bagi seseorang atau sekelompok orang untuk melakukan tindakan anarkis berdasarkan semangat jihad versi mereka. ${ }^{31}$

Ajaran hukum Islam yang ramah, toleran dan damai telah tertutup dengan nash-nash yang keras secara tekstual karena tidak

28 A. Mukti Ali, "Ilmu Perbandingan Agama di Indonesia", dalam Zaini Muhtarom dkk.,(redaksi), Ilmu Perbandingan Agama di Indonesia, (Jakarta: INIS, 1990): A Mukti Ali, Ilmu Perbandingan Agama di Indonesia, (Mizan, Bandung, 1998).

${ }_{29}$ As'ad Said Ali, al-Qaeda: Tinjauan Sosial-Politik Ideologi dan Sepak Terjangnya, (Jakarta: LP3ES, 2014), 142-143 dan 259.

${ }^{30}$ As'ad Said Ali, al-Qaeda: Tinjauan Sosial-Politik Ideologi dan Sepak Terjangnya, (Jakarta: LP3ES, 2014), 254-259.

31 M Amin Abdullah, Pembaharuan Pemikiran Islam dan Perlunya Pendasaran Aqidah, Makalah disampaikan dalam Seminar Internasional kerjasama Universitas Muhammadiyah Prof. Dr. HAMKA dengan Kerajaan Negeri Perlis Malaysia, Hotel Aryaduta, (Jakarta: 19 Februari 2007): http:/ /aminabd.wordpress.com/2010/04/30/pembaharuan-pemikiran-islam-dan-perlunyapendasaran-aqidah/, (diakses tanggal 12 November 2016) 
dipahami secara utuh, walaupun jika dipahami secara mendalam pada dasarnya tidak demikian keadaannya. Jika hukum Islam ditegakkan dalam kerangka legal formal (figh norm) sekaligus substansinya (etic norm), tentu saja akan membawa kemaslahatan bagi umat Islam pada khususnya dan umat manusia pada umumnya. Oleh sebab itu, Ahmad Hasyim Muzadi menyatakan bahwa hukum Islam sebagai prinsip dan pedoman hidup umat Islam harus terinternalisasi sebagai perilaku, bukan hanya sekadar menjadi wacana keilmuan semata. Oleh sebab itu, ia menjelaskan bahwa wacana moderasi hukum Islam harus mampu mewujudkan kemaslahatan hidup manusia dan memberikan ruang kebaikan melalui cara-cara persuasi dan bukan represi. ${ }^{32}$

Gagasan moderasi hukum Islam Ahmad Hasyim Muzadi tersebut pada dasarnya berdasarkan pada gagasan Islam Rahmatan lil Alamin. Adapun ajaran Islam Rahmatan lil Alamin memiliki basis yang kuat dalam norma-norma hukum Islam sebagaimana tertera dalam sejumlah ayat-ayat al-Qur'an yang meliputi: damai (Q.S. al-Anfâl [8]: 61 dan Q.S. al-Hujurât [49]: 9), menyerah (Q.S al-Nisâ [4]: 125 dan Q.S Ali Imrân [3]: 83), penyerahan diri secara totalitas kepada-Nya (Q.S alBaqarah [2]: 208 dan Q.S al-Shaffât [37]: 26), bersih dan suci (Q.S. alSyu'arâ' [26]: 89; Q.S. al-Maidah [5]: 6 dan Q.S. al-Shaffât [37]: 84), selamat dan sejahtera (Q.S. Maryam [19]: 47). 33

Dalam hal yang sama, Alwi Shihab juga menyatakan bahwa wacana moderasi hukum Islam adalah wacana yang relevan untuk diterapkan di Indonesia karena memiliki prinsip berpikir selalu berusaha menafsirkan nash-nash hukum Islam secara utuh untuk menjawab perkembangan aktual di masyarakat, bukan cara berpikir konservatif yang enggan mengakomodir perkembangan zaman dan pemikiran fundamentalis yang enggan menafsirkan nash-nash hukum Islam dengan menggali substansi dan tujuan hukum Islam. Wacana hukum Islam yang paling tepat diterapkan di Indonesia adalah

32 "KH. Hasyim Muzadi: Islam Beri Kebaikan untuk Umat Manusia”

http://walisongoonline.com/hasyim-muzadi-islam-beri-kebaikan-untuk-umat-manusia/, (diakses tanggal 18 Juni 2016)

${ }^{33}$ Muhammad Makmun Rasyid, "Islam Rahmatan lil Alamin Perspektif KH. Hasyim Muzadi", Jurnal Epistemé, Volume 11, No 1 (Juni 2016), 101-102. 
wacana moderasi yang berusaha mendialektikakan antara nash-nash dengan realitas. ${ }^{34}$

Wacana moderasi hukum yang dimaksud, menurut Ahmad Hasyim Muzadi, menyangkut bagaimana tata hubungan yang seimbang antara hukum Islam dengan negara, yakni bagaimana hukum Islam dilindungi Negara, dan negara terinspirasi oleh hukum hukum Islam dengan tetap dalam bingkai nasionalisme, pluralitas dan Negara Kesatuan Republik Indonesia (NKRI), disamping kunjungan lintas agama. Dalam tataran internasional, wacana moderasi hukum Islam yang bersumber dari akar Islam rahmatal lil alamin dibangun untuk mengkampanyekan kedamaian, kerukunan dan keberadaban ke dunia internasional sehingga diharapkan terjadi dialog untuk menyelesaikan kesenjangan antara Barat dan Timur antara lain dengan menggelar International Conference of Islamic Scholars (ICIS) serta melakukan kunjungan-kunjungan ke berbagai negara-negara di Barat seperti Amerika Serikat, Sekretariat WCRP, Thailand Selatan, Syiria, Iran, Vatikan, Uni Eropa, Australia, Inggris, Jerman, Palestina dan Israel. ${ }^{35}$

Adapun wacana moderasi hukum Islam yang hendak dibangun dan diterapkan Ahmad Hasyim Muzadi dapat dijelaskan dalam berbagai bidang, yakni: Pertama, moderasi dalam sistem kehidupan duniawi yang berarti bahwa ada keseimbangan dalam menjaga dan memelihara antara hak-hak asasi manusia dan lingkungan karena kedua-duanya memiliki nilai penting dalam menjaga kelestarian dan kemaslahatan hidup yang berkelanjutan. Kemaslahatan hidup saat ini tidak hanya bagi Muslim tetapi juga non-Muslim. Kedua, moderasi dalam sistem ekonomi, umat manusia akan mencapai kesuksesan dan keberhasilan sebagaimana pernah dilakukan Nabi Muhammad dalam berbagai perjuangannya karena berkat kerja ikhlas dan kerasnya, sehingga sunnatullah berlaku dalam kehidupan umat manusia saat ini. Demikian juga ada keseimbangan dalam distribusi kekayaan sehingga disyariatkan misalnya zakat dan infaq. Ketiga, moderasi dalam tata kehidupan sosial kemasyarakatan

\footnotetext{
${ }^{34}$ Alwi Shihab, Islam Inklusif: Menuju Sikap Terbuka dalam Beragama, (Bandung: Mizan, 1999), hlm. 178-179: James Norman Dalrymple Anderson, Hukum Islam di Dunia Modern, Terj. Machnun Husein, (Surabaya: CV. Amrpress, 1991), 90-91.

35 Saiful Anam, "Konsep Ummah Rahmatan Lil 'Alamin : Studi Atas Pemikiran Hasyim Muzadi", Tesis Magister, ( Surabaya: UIN Sunan Ampel Surabaya, 2016), 113-114.
} 
yang memberikan ketentuan-ketentuan dasar atau pilar-pilarnya saja, sedangkan penerapannya secara detail dan konprehensif tergantung pada kesepakatan dan pemahaman masing-masing komunitas berdasarkan keberagaman lokalitas nilai dan sejarah yang dimilikinya. Keempat, moderasi dalam akidah yang berarti bahwa umat Islam tidak boleh memaksakan akidahnya kepada agama lain tetapi harus menghormati dan menghargai kelompok agama lain. Eksistensi pluralitas diakui sebagai sunnatullah sebagaimana dijelaskan dalam Q.S al-Rum (30): 22, Q.S al-Hujurat (49): 10 dan 13, yang memiliki benang merah yang bisa ditarik dari perintah ini adalah untuk mewujudkan perdamaian dan semua orang harus merasa bersaudara senasib. Kelima, moderasi dalam bidang hukum yang berarti bahwa pemberlakuan hukum tidak hanya berpijak pada formalitasnya saja, tetapi juga sekaligus substansinya. ${ }^{36}$

Dalam tataran empiris, Ahmad Hasyim Muzadi menjelaskan bahwa Nabi saw telah memberikan suri tauladan dalam hidup yang damai dan toleran dalam lingkungan yang majemuk. Ketika di Madinah, ia mendeklarasikan Piagam Madinah yang berisi jaminan hidup bersama yang damai dengan umat agama lain. Gereja atau sinagog dapat menyelenggarakan peribadatan dengan baik dan aman. Inilah tujuan utama dari hukum Islam adalah untuk memberikan kemaslahatan yang hakiki bagi umat manusia. ${ }^{37}$ dengan demikian, wacana moderasi hukum Islam itu hendak menempatkan substansi hukum Islam sebagai tujuan dari pembangunan dan pemberlakuan hukum Islam untuk mewujudkan kemaslahatan hidup umat manusia yang dalam hal ini di Indonesia pada khususnya dan di seluruh dunia pada umumnya, sehingga wacana hukum Islam

\footnotetext{
36 Ahmad Hasyim Muzadi, Islam Rahmatan Lil'alamin Menuju Keadilan dan Perdamaian Dunia: Perspektif Nahdlatul Ulama, Pidato Pengukuhan Doktor Honoris Causa dalam Peradaban Islam disampaikan di Hadapan Rapat Terbuka Senat IAIN Sunan Ampel, (Surabaya: 2 Desember 2006): https://rachmatfatahillah.blogspot.co.id/2012/04/islam-rahmatan-lilalamin-dr-k-hhasyim.html, (diakses tanggal 12 November 2016)

37 Ahmad Hasyim Muzadi, Islam Rahmatan Lil'alamin Menuju Keadilan dan Perdamaian Dunia: Perspektif Nahdlatul Ulama, Pidato Pengukuhan Doktor Honoris Causa dalam Peradaban Islam disampaikan di Hadapan Rapat Terbuka Senat IAIN Sunan Ampel (Surabaya: 2 Desember 2006): https://rachmatfatahillah.blogspot.co.id/2012/04/islam-rahmatan-lilalamin-dr-k-hhasyim.html, (diakses tanggal 12 November 2016)
} 
tidak boleh berpihak kepada kepentingan tertentu yang dapat menjauhkan dari substansi dan tujuan hukum Islam itu sendiri. 38

\section{Penutup}

Berdasarkan uraian tersebut, kajian ini yang merumuskan dua masalah, yakni bagaimana paradigma ijtihad moderat Hasyim Muzadi dalam membangun wacana moderasi hukum Islam? bagaimana moderasi hukum Islam dibangun oleh Ahmad Hasyim Muzadi?, maka dapat disimpulkan bahwa paradigma ijtihad moderat Ahmad Hasyim Muzadi berdasarkan prinsip ajaran Islam rahmatal lil 'alamin menjadi landasan yang paling kokoh dan qath'i dalam pembangunan wacana moderasi hukum Islam, sedangkan wacana moderasi hukum Islam telah memberikan sumbangan yang konkrit dalam menepis asumsi yang salah tentang Islam atau hukum Islam baik di level nasional maupun internasional dan sekaligus memberikan arah penyeimbangan dan pembangunan kemaslahatan hidup umat manusia dalam segala segi kehidupannya baik baik dalam bidang ekonomi akan terjadi pemerataan, dalam bidang sosial akan terjadi hubungan kemasyarakatan yang harmonis, dalam bidang hukum akan terjadi keseimbangan antara penerapan aturan legal dan substansinya, dan dalam bidang agama akan terjadi sikap inklusif terhadap kehadiran agama lain.

\section{Daftar Pustaka}

Abdullah, M Amin, Pembaharuan Pemikiran Islam dan Perlunya Pendasaran Aqidah, Makalah disampaikan dalam Seminar Internasional kerjasama Universitas Muhammadiyah Prof. Dr. HAMKA dengan Kerajaan Negeri Perlis Malaysia, Hotel Aryaduta, (Jakarta: 19 Februari 2007).

Abdullah, M. Amin, Studi Agama; Normativitas dan Historisitas. Yogyakarta: Pustaka Pelajar, 1996.

\footnotetext{
38 A Hasyim Muzadi, Nahdlatul Ulama: Di tengah Agenda Persoalan Bangsa, (Jakarta: PT Logos Pencari Ilmu, 1999): Saiful Anam, “Konsep Ummah Rahmatan Lil 'Alamin : Studi Atas Pemikiran Hasyim Muzadi" (Tesis Magister: UIN Sunan Ampel Surabaya, 2016), hlm. 40-45: http://www.beritasatu.com/nasional/322254-hasyim-muzadi-masyarakat-dunia-kehilanganrasa-spiritualisme.html., (diakses tanggal 12 November 2016).
} 
Abraham, M. Francis, Modernisasi di Dunia Ketiga: Suatu Teori Umum Pembangunan, terj. M. Rusli Karim. Yogyakarta: Tiara Wacana, 1991.

Ali, A Mukti, Ilmu Perbandingan Agama di Indonesia. Bandung: Mizan, 1998.

--_--_-----.-, "Ilmu Perbandingan Agama di Indonesia”, dalam Zaini Muhtarom dkk.,(redaksi). Ilmu Perbandingan Agama di Indonesia. Jakarta: INIS, 1990.

Ali, As'ad Said, al-Qaeda: Tinjauan Sosial-Politik Ideologi dan Sepak Terjangnya. Jakarta: LP3ES, 2014.

al-Syawwâf, Muhâmî Munîr Muhammad Thâhir. Tahâfut al-Qirâ'ah alMu'âshirah. Cyprus: Al-Syawwâf li al-Nasyr wa al-Dirâsât, 1993.

Anam, Saiful, "Konsep Ummah Rahmatan Lil 'Alamin : Studi Atas Pemikiran Hasyim Muzadi", Tesis Magister: UIN Sunan Ampel Surabaya, 2016.

Anderson, James Norman Dalrymple, Hukum Islam di Dunia Modern, Terj. Machnun Husein. Surabaya: CV. Amrpress, 1991.

Bagindo Armaidi Tanjung (Kontributor), Dulu NU Mengislamkan, Kini NU Dikafirkan, http://www.nu.or.id/post/read/35828/dulu-numengislamkan-kini-nu-dikafirkan, (diakses tanggal 12 November 2016)

Baidowi, Ahmad, dkk, (eds.), Rekonstruksi Metodologi Ilmu-ilmu Keislaman. Yogyakarta: Suka Press, 2003.

Barton, Greg, Gagasan Islam Liberal di Indonesia; Pemikiran NeoModernisme Nurcholish Madjid, Djohan Efendi, Ahmad Wahib, dan Abdurrahman Wahid, terj. Nanang Tahqiq. Jakarta: Pramadina, Pustaka Antara, dan The Ford Foundation, 1999.

Burhani, Ruslani, (ed), "Hasyim Muzadi: radikalisme bukan berasal dari Indonesia", http:// www.antaranews.com/berita/571117/hasyimmuzadi-radikalisme-bukan-berasal-dariindonesia?utm_source=related_news\&utm_medium=related \&utm_campaign=news, (diakses tanggal 1 Agustus 2016)

Djamil, Fathurahman, Filsafat Hukum Islam, Jakarta: Logos, 1997.

Dahlan, Moh, "Gagasan Islam Kontemporer M Amin Abdullah". Jurnal Academia Lemlit IAI Nurul Jadid, Vol. 02 tahun 2007. 
Hasan, Ahmad, The Early Developmment of Islamic Jurisprudence. Islamabad: Islamic Research Institute, 1970.

Hasyim Jajaki Kerjasama Deradikalisasi dengan Australia, http:// www.nu.or.id/post/read/56314/hasyim-jajakikerjasama-deradikalisasi-dengan-australia, (diakses 12 November 2016).

"KH A Hasyim Muzadi: Tiga Pola Pemikiran Islam di Indonesia", http://jakartanews.co/kh-hasyim-muzadi-tiga-polapemikiran-islam-di-indonesia/, (diakses tanggal 1 Agustus 2016)

"KH. Hasyim Muzadi: Islam Beri Kebaikan untuk Umat Manusia", http://walisongoonline.com/hasyim-muzadi-islam-berikebaikan-untuk-umat-manusia/, (diakses tanggal 18 Juni 2016)

http://aminabd.wordpress.com/2010/04/30/pembaharuanpemikiran-islam-dan-perlunya-pendasaran-aqidah, (diakses 12 November 2016)

http:/ fitk.uinmalang.ac.id/sites/default/files/materi/Materi $\% 20 \mathrm{Kuliah} \%$ 20Tamu\%20PAI\%202016_.pdf, (diakses tanggal 12 November 2016).

https://id.wikipedia.org/wiki/Hasyim_Muzadi, (diakses tanggal 01 Agustus 2016)

https://rachmatfatahillah.blogspot.co.id/2012/04/islam-rahmatanlilalamin-dr-k-h-hasyim.html, (diakses tanggal 12 November 2016).

Imâm, Muhammad Kamâl al-Dîn, Ushûl al-Fikih al-Islâmî. Iskandariyah: Dâr al-Mathbû' al-Jâmi' iyyah, t.th.

Khallaf, Abdul Wahhab, Ilm Ushûl al-Fiq. Kuwait: Dar al-Qalam, t.th.

Mahfudh, KH MA Sahal, "Islam dan Sistem Perekonomiannya", http:// www.nu.or.id/post/read/62601/islam-dan-sistemperekonomiannya, (diakses tanggal 20 Juni 2016)

Mahfudh, MA Sahal, Nuansa Fiqih Sosial. Yogyakarta: LKiS, 2004.

Munitz, Milton K, Contemporary Analytic Philosophy. New York: Macmillan Publishing, 1981.

Muzadi, A Hasyim, Mengembangkan NU Melalui Penyembuhan Luka Bangsa. Jakarta: PBNU, 2002. 
Nahdlatul Ulama: Di tengah Agenda Persoalan Bangsa. Jakarta: PT Logos Pencari Ilmu, 1999.

-------, Islam Rahmatan Lil'alamin Menuju Keadilan dan Perdamaian Dunia: Perspektif Nahdlatul Ulama, Pidato Pengukuhan Doktor Honoris Causa dalam Peradaban Islam disampaikan di Hadapan Rapat Terbuka Senat IAIN Sunan Ampel (Surabaya: 2 Desember 2006).

Nata, Abuddin, Islam Rahmatan lil Alamin Sebagai Model Pendidikan Islam Memasuki Asean Community, Makalah disampaikan pada acara "Kuliah Tamu" Jurusan Pendidikan Agama Islam Fakultas Ilmu Tarbiyah dan Keguruan UIN Maulana Malik Ibrahim Malang Senin, 7 Maret 2016 di Aula Lt. 5 Gedung Rektorat (Ir. Soekarno), (Malang: 7 Maret 2016).

Rasyid, Muhammad Makmun, "Islam Rahmatan lil Alamin Perspektif KH. Hasyim Muzadi”. Jurnal Epistemé. Volume 11, No. 1 (Juni 2016).

Shihab, Alwi, Islam Inklusif: Menuju Sikap Terbuka dalam Beragama. Bandung: Mizan, 1999.

Suryanto (ed.), "Terorisme Sama Dengan Deislamisasi", http://www.antaranews.com/berita/569356/terorismesama-dengandeislamisasi?utm_source=related_news\&utm_medium=relat ed\&utm_campaign=news, (diakses tanggal 1 Agustus 2016)

Syahid, Achmad, "Peta Kerukunan Umat Beragama Propinsi Bengkulu" (Seri II), dalam Riuh Di Beranda Satu, Peta Kerukunan Umaat Beragama di Indonesia. Jakarta: Depag RI, 2003.

Thufail, Fadjar I, "Ketika "Perdamaian" Terwujud di Bukit Kasih: Pencegahan Konflik, Lembaga Gereja, dan Politik Adat di Minahasa", Martinus Ramstedi dan Fadjar I Thufail (eds). Kegalauan Identitas: Agama, Etnisitas, dan Kewarganegaraan pada Masa Pasca-Orde Baru. Jakarta: Gramedia, 2011. 